\title{
O ESPAÇO GÓTICO E A QUESTÃO DE LEITURA EM NOTHANGER ABBEY DE JANE AUSTEN
}

Priscila Campos*

RESUMO: Northanger Abbey é uma paródia da ficção gótica escrita por Jane Austen e publicada, postumamente em 1818. Austen escreveu esse romance no momento em que a ficção gótica havia alcançado seu clímax de popularidade no final do século XVIII. Austen apresenta, neste romance, um problema de interpretação: a protagonista, Catherine Morland, é incapaz de compreender os limites entre o mundo ficcional e sua realidade. Tal limitação, muitas vezes, é enfatizada através de um aspecto formal da narrativa - o espaço. Catherine constrói sua ilusão através da associação entre o espaço estereotipado do romance gótico e o mundo que a cerca. As dificuldades que Catherine enfrenta não estão apenas ligadas a como Catherine vê o mundo ao seu redor, mas como ela o interpreta. Por esse motivo, este artigo tenciona discutir como o espaço, um aspecto formal da narrativa, é responsável pela ilusão em torno do romance ao qual Catherine está submersa.

PALAVRAS-CHAVE: Espaço; Jane Austen; Leitura; Ficção Gótica
* prica.campos@hotmail.com

Graduada em Letras - habilitação em Língua Inglesa pela

Universidade Federal de Santa Maria (UFSM) - e mestranda do Programa de Pós-graduação em Letras pela mesma instituição.

ABSTRACT: Northanger Abbey is parody of gothic fiction written by Jane Austen and published, posthumously, in 1818. Jane Austen wrote this novel when gothic fiction reached its peak of popularity in the end of the eighteenth century. Austen presents, in this novel, a problem of interpretation: Catherine Morland, is unable of comprehending the boundaries between the fictional world and her living experience. Such limitation, many times, is emphasized through a formal aspect of the narrative; the setting. Catherine builds her illusion through the association between the stereotyped setting of the gothic fiction and the world around her. The difficulic not only related to how she perceives the world around her, but also how she reads it, how she interprets it. For this reason, this article aims to discuss how this formal aspect of the narrative, the setting, is responsible for the illusion surrounding the novel that Catherine is submerse.

KEYWORDS: Setting; Jane Austen; Reading; Gothic Fiction 
1. COLASANTE. A leitura e os leitores em Jane Austen, p. 22

2. COLASANTE. $A$ leitura $e$ os leitores em Jane Austen, p. 22

3. VASCONCELOS. A formação do romance inglês, p.213

\section{INTRODUÇÃO}

Indubitavelmente, Jane Austen (1775-1817) é uma autora de suma importância no cenário da literatura inglesa na virada do século XVIII para o século XIX. O talento da romancista é notável desde seus romances mais complexos àqueles considerados menores pela crítica como, por exemplo, Northanger Abbey, escrito quando a autora tinha entre 22 e 23 anos de idade. Em Northanger Abbey, Austen discute questões relacionadas ao panorama social de sua época e à tradição literária vigente por meio do emprego de técnicas narrativas peculiares que se tornaram características de sua escrita. Northanger Abbey é uma paródia do romance gótico e Austen a escreveu em diálogo com a crescente produção de romances góticos "que aceleravam o ritmo das prensas das casas editorais especializadas em romances, na década de 1790"1. A demanda do mercado por esse tipo de narrativa fez com que alguns romances publicados anteriormente passassem a ser "reciclados e transformados em novos romances"2. Sandra Vasconcelos denomina essa prática como "plágios e maquiagens de obras encalhadas"3 usados para suprir a ânsia mercadológica. Desse modo, nota-se que Jane Austen era uma escritora atenta à produção literária de sua época, pois escreveu Northanger Abbey no período em que o romance gótico alcançava o auge de sua produção e consumo. Interessantemente, em Northanger Abbey, Austen não critica o romance gótico como gênero, mas posiciona-se contra a banalização a qual o gênero havia sido submetido. Tal crítica concentra-se, principalmente, no papel da protagonista do romance: Catherine Morland.

Logo na abertura do romance o narrador testifica que, "no one who had ever seen Catherine Morland in her infancy, would have supposed her born to be an heroine"4. Catherine, no primeiro capítulo de Northanger Abbey, é apresentada como uma protagonista despreparada, desarmonizada com o papel comum das heroínas da ficção gótica. De acordo com o narrador, a personagem é uma jovem comum que prefere jogar cricket a ler livros. Além disso, segundo o narrador, a mente da protagonista não é inclinada ao heroísmo ${ }^{5}$. Dessa forma, Catherine é apresentada como uma personagem completamente oposta ao padrão de heroína estereotipado pela ficção gótica: Catherine não é bela, não é inteligente e não corresponde às qualidades dessas heroínas. Além do mais, a protagonista de Austen tem a imaginação "irremediavelmente contaminada pelas leituras deste tipo de ficção [gótica]". No decorrer da narrativa, Catherine torna-se uma leitora obcecada por romances góticos, incapaz de estabelecer os limites entre o que lê e sua experiência de vida. Tal problema de interpretação está ligado à associação que a heroína constrói entre o mundo ao seu redor e as convenções literárias usadas no espaço da ficção gótica. Por esse motivo, este artigo discutirá como o espaço, um aspecto formal da narrativa, é um dos fatores responsáveis pela ilusão em torno do romance ao qual Catherine está submersa.
5. AUSTEN. Northanger Abbey, p.15,16

6. VASCONCELOS. Dez lições sobre o romance inglês do século XVIII, p 185
EM TESE BELO HORIZONTE $\quad$ v. $22 \quad$ N. 1 JAN.-ABr. 2016 CAMPOS. 0 espaço gótico e a questão de leitura em Nothanger Abbey [...] P. 123-131

\section{Crítica Literária, outras Artes e Mídias}


7. JERROLD. Introduction: the gothic in western culture. In: The Cambridge Companion to Gothic Fiction, p. 2

\section{O ESPAÇO NA FICÇÃO GÓTICA}

De acordo com Jerrold E. Hogle ${ }^{7}$ os eventos da ficção gótica ocorrem, normalmente, em lugares arcaicos e primitivos como castelos antigos, palácios estrangeiros e abadias. Tais lugares geralmente escondem segredos, passados ou recentes, que assombram as personagens, fisicamente e psicologicamente. O espaço, na tradição da ficção gótica, tornou-se como um símbolo ou ícone do gênero em si. Não é incomum, no auge da produção desses romances, encontrar obras cujos títulos remetem ao espaço da narrativa como: The Castle of Wolfenbach (1793), de Eliza Parsons; Necromancer of the Black Forest (1794), de Carl Frederich Kahlert; The Castle of Otranto (1764), de Horace Walpole; e tantos outros. Certamente, a sistematização da construção do espaço na ficção gótica foi essencial para a consolidação do gênero gótico. Uma importante autora nesse processo, sem dúvida, é Ann Radcliffe (1764 - 1823). Não é de admirar que o romance mais importante de Radcliffe, The Mysteries of Udolpho (1794), seja a obra que a protagonista de Jane Austen lê em Northanger Abbey.

A popularidade do romance gótico no final do século XVIII, de acordo com alguns críticos, deve-se, em grande parte, à oposição do gênero ao realismo e racionalismo que fora dominante na chamada Era da Razão. Assim como os demais autores de sua época, os romances de Ann Radcliffe apresentam lugares arcaicos e assustadores, personagens assombradas por fantasmas, suspense e mistério. Contudo, no final das narrativas de Radcliffe, todos os aspectos "sobrenaturais" comuns à ficção gótica eram explicados racionalmente. Sandra Vasconcelos ${ }^{8}$ esclarece que Ann Radcliffe

Combinou e harmonizou tendências românticas de sua época, acrescentando-lhes efeitos pictóricos, o sentimento do medo e o esplendor natural. Da mesma forma, Radcliffe reuniu, retomou o enredo do romance sentimental, calcado nas atribuições de uma bela e solitária jovem envolvida em perigos de toda a ordem, e envolve-o em mistério e suspense, providenciando paisagens magníficas e pitorescas, câmaras mortuárias e propriedades em ruinas como cenário para suas histórias que conjugam beleza e terror. A criação da atmosfera e a sugestão de terror, mais do que sua encenação crua e direta, são traços que distinguem a autora de The Mysteries of Udolpho de seus antecessores [...].

No fragmento acima, Sandra Vasconcelos destaca importantes características da obra de Radcliffe - o "efeito pictórico" e as paisagens "magníficas e pitorescas" encontrados em seus romances. Sem dúvida, as vívidas descrições dos cenários de The Myteries of Udolpho teriam estimulado Catherine a imaginar excessivamente e, em consequência, contribuíram para sua confusão entre os limites do mundo ficcional e a sua realidade. Essa confusão fica evidente nas associações
8. VASCONCELOS. Dez lições sobre o romance inglês do século XVIII p. 127
EM TESE
BELO HORIZONTE
v. 22
N. 1
JAN.-ABR. 2016
CAMPOS. 0 espaço gótico e a questão de leitura em Nothanger Abbey [...] P. 123-131

Crítica Literária, outras Artes e Mídias 
9. VASCONCELOS. Dez liçôes sobre o romance inglês do século XVIII, p. 118 diretas que a protagonista faz entre o espaço ao seu redor e o cenário típico da ficção gótica.

De fato, Jane Austen procurou ambientar bem o seu romance - em uma abadia. Assim sendo, é justamente no segundo volume de Northanger Abbey, localizado nessa abadia, que Catherine perde o controle sobre sua imaginação e comete o seu maior erro: imaginar que a mãe de Henry, o herói do romance, teria sido morta pelo pai dele, General Tilney. A Abadia de Northanger, como uma representação de todo o terror vivido por Catherine através dos romances que leu, faz com que ela instigue seus devaneios além do que é socialmente aceitável. Esse lugar tão explorado pela ficção gótica fomenta e influencia o modo da protagonista ver o mundo ao redor e a leva, em consequência, ao erro e à decepção. Ao contrário de suas expectativas, Catherine não encontra perigos na abadia de Northanger na realidade, os excessos de sua própria imaginação a cegam para a realidade de que "a vida, apesar de ser por vezes estranha e violenta, não é semelhante a um romance gótico" . No entanto, é justamente o contato de Catherine com a leitura de ficção gótica e a aprendizagem de seus erros que a levam a se tornar, no final da narrativa, a típica heroína da ficção gótica.

\section{O ESPAÇO EM NORTHANGER ABBEY}

No primeiro volume do romance, os eventos da narrativa concentram-se na cidade de Bath e no segundo volume na Abadia de Northanger. No primeiro capítulo (volume I), como já mencionado, Catherine é apresentada pelo narrador como uma protagonista que não atinge o padrão de heroína da ficção gótica. Depois de se instalar em Bath, Catherine conhece Isabella Thorpe, personagem que introduz a protagonista à leitura de romances góticos. Em diversos capítulos do volume I, as personagens discutem a leitura de The Mysteries of Udolpho. Catherine é atraída pelo suspense explorado pela ficção gótica, pois, após Isabella mencionar uma lista de romances que pretende ler, Catherine pergunta; "are you sure, they are all horrid?"10. J. M. S Tompkins ${ }^{11}$ explica que na ficção gótica o leitor não é apenas convidado a desatar um nó, mas desfrutar da emoção do mistério, ou seja, o suspense da ficção gótica envolve e prende a atenção do leitor - o que ocorre em alto grau com Catherine. O espaço explorado por esse tipo de narrativa tem um papel fundamental para a criação do efeito de suspense.

Ademais, a ficção gótica, normalmente, apresenta lugares antigos e sombrios envoltos em penumbra e em horror, isolados ou distantes dos grandes centros urbanos. Tais cenários longínquos, em lugares esquecidos, permitem que a história apresente casos que envolvam parricídio, infanticídio, uxoricídio, incesto e etc. Por esse motivo, Catherine facilmente supõe que General Tilney tenha matado sua esposa, porquanto uma abadia seria um lugar apropriado
0. AUSTEN. Northanger Abbey, $\mathrm{p}$

11. TOMPKINS. The Gothic Romance. In: The Popular Novel in England: $1770-1800$, p.262
EM TESE BELO HORIZONTE $\quad$ v. $22 \quad$ N. 1 JAN.-ABr. 2016 CAMPOS. 0 espaço gótico e a questão de leitura em Nothanger Abbey [...] P. 123-131 
12. AUSTEN. Northanger Abbey, p.81 para cometer esse tipo de atrocidade. O suspense, o horror e o medo criados pelo espaço da ficção gótica são fatores importantes para que Catherine torne-se obcecada por castelos antigos e abadias. No capítulo XI, volume I, Catherine é convidada por seu irmão, James Morland, Isabella e Johrn Thorpe, para visitar Blaize Castle. Quando Isabella menciona que este é um dos castelos mais antigos da Inglaterra, Catherine faz a seguinte pergunta: "but it is like what one reads of?"12. Catherine fica tão absorta pela ideia de conhecer um castelo igual aos romances que leu que deixa de cumprir um compromisso anterior: passear com Henry Tilney e sua irmã. A protagonista é tomada pelo "delight of exploring an edifice like Udolpho, as her fancy represented Blaize Castle to be [...]"13. O narrador deixa claro que as comparações e aproximações entre o cenário da ficção gótica e a experiência vivida pela protagonista é estabelecida por "her fancy", ou seja, pela imaginação de Catherine. No entanto, pouco a pouco, de acordo com o desenvolvimento da narrativa, a protagonista passa a confundir os limites entre o mundo ficcional e sua experiência de vida - confusão que se intensifica na passagem do volume I para o volume II.

No capítulo V do volume II, Catherine e Henry viajam para a Abadia de Northanger. O diálogo entre os personagens, durante o trajeto que percorrem, expõe o quanto a protagonista está influenciada pelo espaço típico da ficção gótica. No início do diálogo, conversando sobre a abadia, ela faz a seguinte pergunta: "Is not it a fine place, just like what one reads about?"14. Mais uma vez, a heroína associa o espaço no qual está inserida ao espaço comum à ficção gótica. Além do mais, essa associação espacial implica em uma relação de significados, ou seja, a abadia de Northanger não tem apenas a mesma arquitetura das abadias da ficção gótica, como também carrega todo o terror, mistério, suspense e perigos das construções ficcionais. Após a pergunta mencionada, Henry, em uma longa fala, passa a descrever todos os estereótipos encontrados na ficção gótica: saguão mal iluminado, lareiras com pequenas fagulhas de fogo, quartos sem janelas, a presença de uma velha governanta, histórias mal-assombradas, mobílias antigas com compartimentos falsos, passagens secretas, noites de tormenta, portas sem trincos, entre outros. Contudo, ele descreve essa cena referindo-se a uma "young lady" ${ }^{15}$ que se depara com essa situação - referência explícita às heroínas desprotegidas da ficção gótica. Catherine fica tão impressionada que exclama; "This is like a book!" ${ }^{16}$. Não é de admirar que Henry faça tal detalhamento, pois em uma de suas conversas localizadas no volume I ele afirma o seguinte para Catherine:

I have read all Mrs. Radcliffe's works, and almost them with great pleasure. The Mysteries of Udolpho, when I have once begun it, I could not lay down again - I remember finishing it in two days - my hair standing on end the whole time ${ }^{17}$
14. AUSTEN. Northanger Abbey, p. 149

15. AUSTEN. Northanger Abbey p.149

16. AUSTEN. Northanger Abbey p.150

7. AUSTEN. Northanger Abbey, p.103
EM TESE
BELO HORIZONTE
v. 22
N. 1
JAN.-ABR. 2016
CAMPOS. 0 espaço gótico e a questão de leitura em Nothanger Abbey [...] P. 123-131

Crítica Literária, outras Artes e Mídias 
A descrição de Henry sobre o que Catherine encontraria na Abadia de Northanger, caso as coincidências da ficção gótica fossem possíveis, está carregada de alusões aos romances que ele mesmo leu. Além disso, há dois aspectos importantes na fala de Henry. Primeiro, a descrição que Henry faz no diálogo com Catherine não é estática, mas indica um movimento. De início, Henry fala da chegada da heroína à abadia percorrendo um saguão mal iluminado. Ela é conduzida pela governanta e acomodada em um quarto longe da família. Essa heroína passará por uma escadaria e por corredores escuros até chegar a um quarto sombrio e imenso, revestido por tapeçarias. Nele, ela achará um baú antigo e, depois, na segunda noite de estadia, sentirá o terror de uma noite tempestuosa. Dessa forma, Henry constrói uma descrição que vai do exterior - lugar onde a protagonista ainda tem algum tipo de proteção - para o interior - o quarto, dentro de um edifício antigo e mal-assombrado. Segundo, embora a descrição de Henry seja detalhista, a mesma não limita a imaginação de Catherine por dar-lhe um cenário "pronto", ao contrário, tal detalhamento instiga ainda mais o devaneio da protagonista. Nos momentos em que Catherine delira e imagina excessivamente, há citações e relações explícitas ao diálogo citado.

A imaginação da protagonista, já fomentada pelas descricões de Henry, e as leituras prévias no primeiro volume do romance, é instigada pela presença de um antigo baú e um armário em seu quarto de hóspedes. No capítulo VI, volume II, Catherine, apesar de reconhecer que esta é uma abadia reformada e moderna, fica intrigada com a presença de um velho baú. Esse objeto chama atenção por ter a letra $T$ gravada em sua madeira. No momento em que a protagonista está curiosa com objeto, através do discurso indireto livre, o narrador faz o seguinte comentário:

She could not, in whatever direction she took it, believe the last letter to be a $\mathrm{T}$; and yet that it should be anything else in that house was a circumstance to raise no common degree of astonishment. If not originally theirs, by what strange events could it have fallen into the Tilney family? ${ }^{18}$

O fragmento acima exemplifica como, rapidamente, Catherine relaciona a presença do baú em seu quarto com 'eventos estranhos' ocorridos na família Tilney. Apesar de reconhecer que esta abadia é diferente, pois não é o ambiente escuro, sombrio com aspectos mórbidos iguais aos romances que leu, este objeto antigo, entre tantos modernos, desperta a curiosidade da protagonista. Certamente, um baú é um objeto comum no cenário da ficção gótica e está diretamente relacionado a segredos antigos - se as personagens têm algo a esconder, está escondido em um baú. Porém, a decepção causada ao não encontrar nada dentro do baú não
18. AUSTEN. Northanger Abbey, p. 155,156
EM TESE
BELO HORIZONTE
v. 22
N. 1
JAN.-ABR. 2016
CAMPOS. 0 espaço gótico e a questão de leitura em Nothanger Abbey [...] P. 123-131

Crítica Literária, outras Artes e Mídias 
19. AUSTEN. Northanger Abbey p.158

20. AUSTEN. Northanger Abbey, p.158 é capaz de parar a inventividade da heroína. Após esse episódio, Catherine vê-se confrontada com uma situação aterrorizante como descrito no fragmento abaixo:

The night was stormy; the wind had been rising at intervals the whole afternoon; and by the time the party broke up, it blew and rained violently. Catherine, as she crossed the hall, listened to the tempest with sensations of awe; and, when she heard it rage round a corner of the ancient building and close with sudden fury a distant door, felt for the first time that she was really in an abbey. Yes, these were characteristic sounds; they brought to her recollection a countless variety of dreadful situations and horrid scenes, which such buildings had witnessed, and such storms ushered in; and most heartily did she rejoice in the happier circumstances attending her entrance within walls so solemn! ${ }^{19}$

A noite tempestuosa, o vento uivante e a chuva torrencial fizeram com que Catherine se sentisse realmente em um abadia. Para ela, a tempestade produzia "sons característicos" que trouxeram à sua memória "situações apavorantes" e "cenas horripilantes", testemunhadas por edifícios como aquele precedidas por "tempestades como aquela"20. Mas, afinal, quais são as situações e cenas às quais Catherine se refere? Quais edifícios e tempestades ela remete? Neste fragmento, através do discurso indireto livre, o narrador expressa as comparações que Catherine estabelece entre aquela noite tempestuosa e as noites tempestuosas da ficção gótica. Os dois elementos, a abadia e a tempestade, ativam a imaginação da protagonista e instigam a sua próxima investigação: com luz de um candelabro, Catherine inspeciona um armário antigo. No início de sua investigação, o narrador faz o seguinte comentário:

Henry's words, his description of the ebony cabinet which was to escape her observation at first, immediately rushed across her; and though there could be nothing really in it, there was something whimsical, it was certainly a very remarkable coincidence! ${ }^{21}$

21. AUSTEN. Northanger Abbey p.159

A presença do armário antigo no quarto de Catherine, associada à vívida descrição de Henry, parece ser uma coincidência impressionante para a protagonista. Desse modo, fica evidente a importância do diálogo citado. Tanto a leitura do romance de Ann Radcliffe, no primeiro volume da narrativa, quanto a descrição de Henry, no segundo volume do romance, impulsionam Catherine a imaginar demais. Assim, ela não consegue dormir antes de examinar o armário. As mãos trêmulas, a vela que ilumina a escuridão da noite, a dificuldade de abrir a fechadura - todos esses elementos criam tensão na descrição - parece que Catherine está prestes a descobrir o que procura. O narrador ambientaliza esse momento descrevendo o vento uivando na chaminé e a chuva
EM TESE
BELO HORIZONTE
v. 22
N. 1
JAN.-ABR. 2016
CAMPOS. 0 espaço gótico e a questão de leitura em Nothanger Abbey [... ] P. 123-131

Crítica Literária, outras Artes e Mídias 
batendo na janela em enxurrada - o típico momento de horror. O suspense em torno dos segredos guardados dentro do armário é quebrado pela vitória de Catherine ao abrir as gavetas e a grande revelação: estavam todas vazias e não possuíam um fundo falso. Porém, Catherine acha, no espaço central do armário, um manuscrito. No dia seguinte, na luz da manhã e da razão, a heroína percebe que o manuscrito é, na verdade, contas antigas de lavanderia.

O fragmento mencionado não se caracteriza como uma interrupção do fluxo narrativo com o objetivo de criar suspense. Assim como a cena mencionada anteriormente, essa descrição não é estática. De fato, o que acontece nesta passagem é um movimento do exterior em direção ao interior. Primeiramente, o narrador descreve a tempestade batendo nas paredes e janelas da abadia, em seguida, o quarto de Catherine, após, o interior do armário e, por fim, o interio da personagem. Nesse mesmo movimento, o detalhamento sobre as reações e sensações da protagonista também se intensificam. No estado inicial, a descrição, de modo geral, está relacionada ao ambiente exterior - à tempestade. Porém, conforme esse detalhamento vai se interiorizando, para o quarto de Catherine e o armário, tem-se acesso às sensações da personagem. Como leitores, vemos as mão trêmulas de Catherine, ouvimos o seu coração pulsando, ouvimos as palavras de Henry martelando em sua mente e nos decepcionamos com ela. Ademais, um dos fatores mais importantes a ser destacados no episódio do baú e do armário é que ambos não são capazes de trazer Catherine à realidade. Desde o início do volume II, Catherine vai interpretando, gradualmente, as situações ao seu redor através das lentes distorcidas da ficção. Esse problema interpretativo cresce até o ponto máximo da narrativa - o confronto entre Henry e Catherine no qual a suspeita do assassinato da mãe do herói é revelada. Nos exemplos citados vê-se que Catherine, uma leitora ingênua e imatura, é incapaz de reconhecer que as convenções ficcionais não podem ser empregadas à sua própria experiência de vida.

\section{CONSIDERAÇÕES FINAIS}

Em Northanger Abbey, percebe-se que Catherine confunde as fronteiras entre a ficção e a realidade através da associação visual; ou seja, a relação entre o espaço em que está inserida e o espaço ficcionalizado pelos romances góticos. Tais associações induzem Catherine a cometer erros sucessivos, os quais indicam, portanto, sua incapacidade de visibilidade intelectual. Essa incapacidade diz respeito a compreender que as convenções ficcionais são apenas plausíveis no mundo ficcional. Catherine só entende isto após a intervenção de Henry no capítulo IX, volume II. Já no capítulo seguinte, o narrador comenta: "the visions of romance were over. Catherine was completely awaked"22. O que faz alusão ao despertar da protagonista ao encontro da luz do dia e da razão.
22. AUSTEN. Northanger Abbey, p. 187
EM TESE BELO HORIZONTE $\quad$ v. $22 \quad$ N. $1 \quad$ JAN.ABR. 2016 CAMPOS. 0 espaço gótico e a questão de leitura em Nothanger Abbey [...] $\quad$ P. 123-131

\section{Crítica Literária, outras Artes e Mídias}


23. AUSTEN. Pride and Prejudice, p. 246
Assim, percebe-se que Jane Austen, em Northanger Abbey, não estava apenas denunciando a falta de originalidade $e$ qualidade a qual a ficção gótica havia sido submetida no final do século XVIII, mas, também, criticava a leitura ingênua que não provoca - como enfatizado por Mr. Darcy em Pride and Prejudice - o aprimoramento da mente ${ }^{23}$. De acordo com o famoso personagem de Austen, esse aprimoramento da mente só pode ser alcançado através de excessiva leitura. Jane Austen, em seus romances, defende a necessidade de uma leitura atenta que possa tornar o leitor crítico de si mesmo e do mundo em que está inserido. Para autora, o alcance da maturidade intelectual é fruto de uma mente enriquecida pela leitura. Desse modo, percebe-se que a ingenuidade de Catherine e seu despreparo como leitora de ficção e do mundo ao seu redor são fatores decisivos para a sua falta de maturidade emocional e intelectual. Porém, é a partir do reconhecimento de seus erros interpretativos que Catherine consegue, ao final da narrativa, alcançar o status de heroína e, enfim, está apta para ver o mundo e a si mesma com clareza.

\section{REFERÊNCIAS}

AUSTEN, Jane. Northanger Abbey. London: Penguin Classics, 1995

AUSTEN, Jane. Pride and Prejudice. São Paulo: Landmark, 2011.
COLASANTE, Renata. A leitura e os leitores em Jane Austen. 2005. Dissertação (Mestrado em Estudos Linguísticos e Literários em Inglês) - Faculdade de Filosofia, Letras e Ciências Humanas, Universidade de São Paulo, São Paulo. 2005.

JERROLD, E. Hogle. Introduction: the gothic in western culture In: JERROLD, E. Hogle (Org). The Cambridge Companion to Gothic Fiction. Cambridge: Cambridge University Press: 2002, p $1-22$

TOMPKINS, Joyce. The Gothic Romance In: TOMPKINS, Joyce. The Popular Novel in England: 1770-1800. London: Methuen, 1969. p.243-295.

VASCONCELOS, Sandra. A formação do romance inglês. São Paulo: FAPESP, 2007

VASCONCELOS, Sandra. Dez lições sobre o romance inglês do século XVIII. São Paulo: Boitempo Editorial, 2002
EM TESE
BELO HORIZONTE
v. 22
N. 1
JAN.ABR. 2016
CAMPOS. 0 espaço gótico e a questão de leitura em Nothanger Abbey [... ] P. 123-131

Crítica Literária, outras Artes e Mídias 